\title{
Dermoscopy of early melanomas: variation according to the anatomic site
}

\author{
Linda Tognetti ${ }^{1}$ - Alessandra Cartocci ${ }^{1,2}$ (1) Elisa Cinotti ${ }^{1} \cdot$ Elvira Moscarella ${ }^{3} \cdot$ Francesca Farnetani ${ }^{4}$. \\ Cristina Carrera ${ }^{5} \cdot$ Aimilios Lallas $^{6} \cdot$ Danica Tiodorovic $^{7}$. Caterina Longo ${ }^{8} \cdot$ Susana Puig ${ }^{5}$. Jean Luc Perrot ${ }^{9}$. \\ Giuseppe Argenziano ${ }^{3}$. Giovanni Pellacani ${ }^{4} \cdot$ Gennaro Cataldo ${ }^{2} \cdot$ Alberto Balistreri $^{2} \cdot$ Gabriele Cevenini $^{2}$. \\ Pietro Rubegni ${ }^{1}$
}

Received: 5 November 2020 / Revised: 18 March 2021 / Accepted: 19 March 2021 / Published online: 26 March 2021

(c) The Author(s) 2021

\begin{abstract}
To date, is yet to be elucidated whether the body location of cutaneous melanoma can significantly affect an early dermoscopic diagnosis and, consequently, if it can be regarded as a prognostic factor. To investigate the dermoscopic appearance of early melanomas (EMs) at different body sites; to test the ability of dermoscopists in recognizing specific dermoscopic features in EMs. A pool of 106 experienced dermoscopists evaluated the presence of 10 dermoscopic features assumed as suggestive of malignancy among 268 images of EMs with ambiguous appearance located at 16 body sites. According to 720 evaluations, EMs of the "upper extremities" showed a prevalence of early atypical lentiginous features. EMs of the "anterior trunk" exhibited the lower rate of recognition for all features. EMs of the "rear trunk" can be regarded as an intermediate area, showing high recognition rates of regression-related and chronic-traumatism-related features.
\end{abstract}

Keywords Dermoscopy $\cdot$ Melanoma $\cdot$ Body site $\cdot$ Early diagnosis $\cdot$ Dermoscopic features

\section{Introduction}

Alessandra Cartocci

alessandra.cartocci@dbm.unisi.it

1 Dermatology Unit, Department of Medical, Surgical and Neurosciences, University of Siena, Siena, Italy

2 Bioengineering and Biomedical Data Science Lab, Department of Medical Biotechnologies, University of Siena, Siena, Italy

3 Dermatology Unit, University of Campania Luigi Vanvitelli, Naples, Italy

4 Department of Dermatology, University of Modena and Reggio Emilia, Modena, Italy

5 Melanoma Unit, Department of Dermatology, University of Barcelona, Barcelona, Spain

6 First Department of Dermatology, Aristotele University, Thessaloniki, Greece

7 Dermatology Clinic, Medical Faculty, Nis University, Nis, Serbia

8 Centro Oncologico ad Alta Tecnologia Diagnostica, Azienda Unità Sanitaria Locale-IRCCS di Reggio Emilia, Reggio Emilia, Italy

9 Dermatology Unit, University Hospital of St-Etienne, Saint Etienne, France
Cutaneous melanoma (MM) incidence has been rising in the last decades, and, in parallel, the attention for its etiology and predisposing factors [2, 3, 5, 7-12]. In this context, the body distribution was of interest both for the clinical relevance and for a better understanding of the etiology of the tumor itself [17-19, 24, 27, 30]. While similar incidence rates for usually and intermittently exposed body sites were reported in the 80 s $[5,8,11,12,17]$, an age-related trend appeared in the last decades, due to changes in clothing and photo-exposure habits: under the age of 50, the upper back showed the highest incidence rates in both sexes [2,3], followed by the lower limb in women used to intermittent sun exposure $[10,30]$; over the age of 50 , the head was mostly involved [7, 24].

The diagnostic utility of dermoscopy for the management of melanocytic skin lesions is today undoubted [13, 14, 26]. In particular, the recognition of a series of features generally accepted as suggestive of malignancy is well established and recommended to recognize MM [27], being the number of displayed malignancy-related features dependent from the MM stage. To date, some specific dermoscopic clues are 
well documented for facial and palmo-plantar MM and demonstrated to be useful in early diagnosis of early melanomas (EMs) (i.e., stage 0 and I) [6, 21, 23]. However, it remains to be described if and/or which specific features are exhibited by EMs at different body sites excluding palms, soles and face. Moreover, it is yet to be elucidated if and how the body location of an EM affects its dermoscopic appearance and, consequently, its impact on the recognition by dermoscopists $[22,25,29]$.

In this study, we first aimed to describe, in a large dataset of EMs, developed at different body sites of the trunk and extremities, the distribution of ten dermoscopic features currently accepted as suggestive for malignancy among [29]; second, to test if dermoscopists were adequately trained to recognize specific subsets of dermoscopic features in EMs localized at four different macro-areas (anterior/posterior trunk, upper/lower extremities) and, third, to individuate at which body site EM can be considered featureless.

\section{Methods}

\section{Study design and population}

This retrospective study was approved by local ethical committee (Protocol No. 16801); all data were deidentified before use. A total of 268 cases of EMs including in situ, stage I, IIA (pt3a) [20], were retrospectively collected from the whole body surface: lesions were consecutively excised during skin tumor screening activity of dermatologic units from 8 different European centers [29]. Only lesions that were judged as "challenging" according to three out four expert dermoscopists were selected, namely: those cases that, based on the dermoscopic appearance only, may not be clearly differentiated from a dysplastic nevus; thus, being the dermoscopic diagnosis of malignancy was not obvious, they could be considered dermoscopically ambiguous cases. Facial, palmo-plantar and mucosal sites were excluded due to peculiar dermoscopic patterns. Patients, 146 males (54.5\%) and 122 females (45.5\%), had a mean age of $56 \pm 16$ years. One dermoscopic, polarized, $>1.5 \mathrm{MPx}$ image per case was collected.

\section{Dermoscopic analysis}

All images were independently evaluated in a teledermoscopic setting by 106 dermatologists with more than 5 -year experience in dermoscopy recruited from 14 different European countries [10]. Each dermatologist, blinded for the histological diagnosis, was required to assess the presence or absence of 11 dermoscopic accepted to be suggestive of malignancy (Table 1), including: atypical network (ANet), irregular streaks (IS), irregular dots and globules (IDG), blue-white veil (BWV), blue-grey peppering (BGP), white scar-like areas (WSA), shiny white streaks (SWS), atypical vascular pattern (AVP), irregular blotches (IB) and regression structures (RS). During teletesting, a total of 30 blinded cases (Fig. 1), matched with data concerning patient age, sex, maximum diameter of the lesion and body location, was randomly assigned to each participant dermoscopist.

Table 1 Definition of 11 dermoscopic features (adapted from ref.23, 24)

\begin{tabular}{|c|c|c|}
\hline Dermoscopic feature & Abbreviation & Definition \\
\hline Atypical network & ANet & $\begin{array}{l}\text { Network with increased variability in the color, thickness, and spacing of the lines of the network; } \\
\text { asymmetrically distributed; gray color }\end{array}$ \\
\hline Irregular streaks & IS & $\begin{array}{l}\text { Peripheral brownish to black lines/pseudopods of variable thickness and length, not combined with } \\
\text { pigment network lines }\end{array}$ \\
\hline Irregular dots and globules & IDG & $\begin{array}{l}\text { Sharply circumscribed, round to oval, brown to black structures of variously sized and irregular } \\
\text { distribution (i.e., neither distributed all over the lesion nor clustered at the center of the lesion, nor } \\
\text { located on the network lines) }\end{array}$ \\
\hline Blue-white veil & BWV & An irregular shaped blotch of blue hue with an overlying whitish ground-glass haze \\
\hline Blue-grey peppering & BGP & fine dots with a blue-gray color (i.e., pepper-like structures) \\
\hline White scar-like area & WSA & Irregular areas with a scar-like appearance and white to whitish color \\
\hline Shiny white streaks & SWS & $\begin{array}{l}\text { Short discrete white lines oriented parallel and orthogonal (perpendicular) to each other, of shiny } \\
\text { white colour, seen only under polarized dermoscopy }\end{array}$ \\
\hline Atypical vascular pattern & AVP & $\begin{array}{l}\text { presence of polymorphic vessels (i.e., two or more of the following type of vessels: linear-irregular, } \\
\text { hairpin, dotted, linear, corkscrew) and/or milky-red areas not within regression structures }\end{array}$ \\
\hline Irregular blotches & IB & More than one blotch (i.e., dark structureless area) or a blotch that is located off the center \\
\hline Regression structures & RS & $\begin{array}{l}\text { White scar-like depigmentation and/or blue pepper-like granules usually corresponding to a clini- } \\
\text { cally flat part of the lesion }\end{array}$ \\
\hline
\end{tabular}


Fig. 1 Examples of early melanomas (EM) of $6 \mathrm{~mm}$ maximum diameter at different anatomical sites, including the arm of a 39-year-old male (a), the upper back of a 34-year-old female (b), the breast of a 44-yearold female (c), the chest of a 48-year-old male (d), the abdomen of a 23-year-old female (e) and the leg of a 26-year-old male (f). The dermoscopic feature "atypical network" largely varies among different body sites, e.g.: dark and pronounced in EM of the posterior trunk and extremities, light and delicate in $\mathrm{EM}$ of the anterior lower trunk

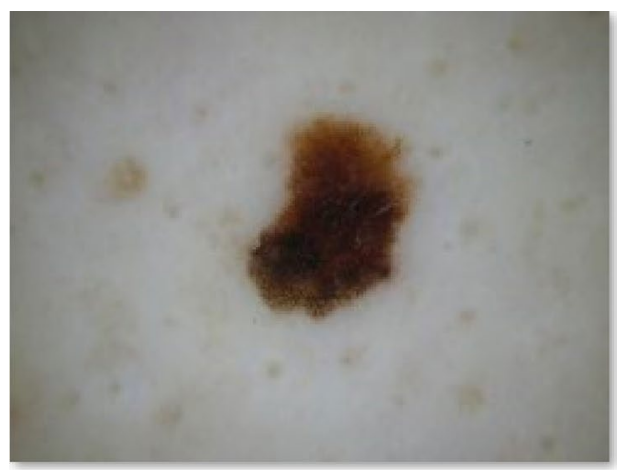

a

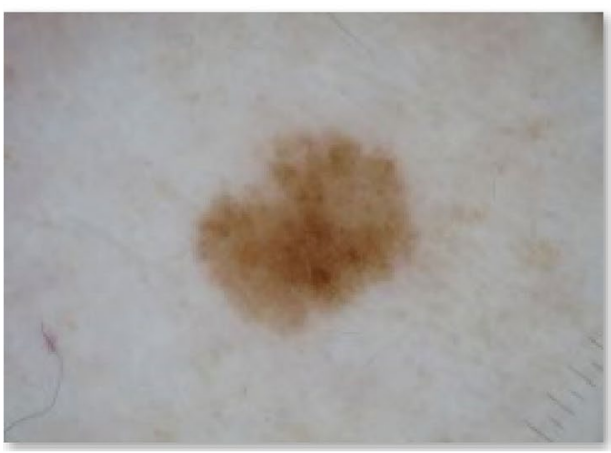

C

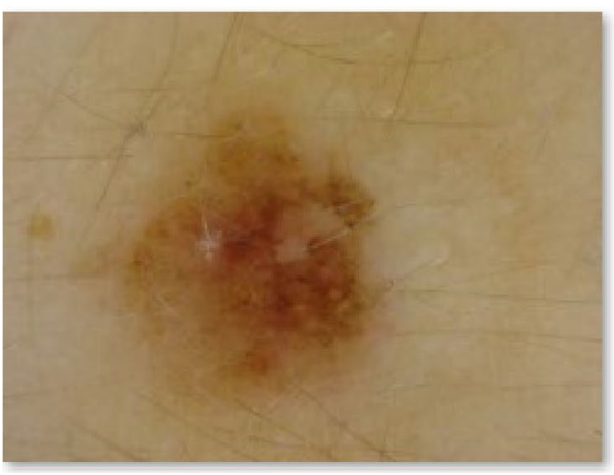

e

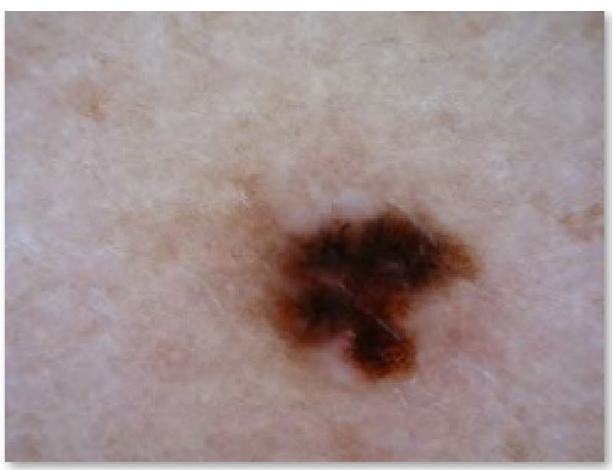

b

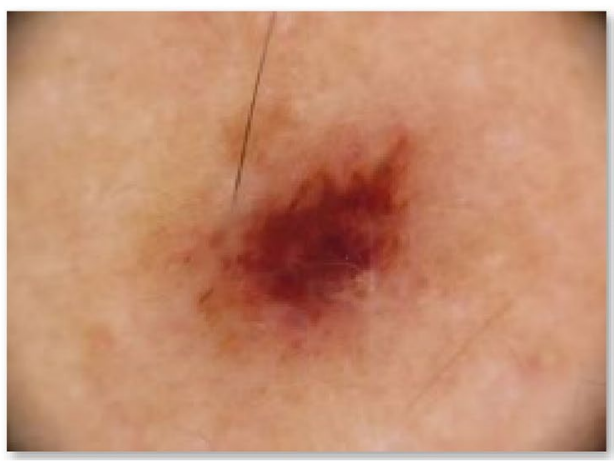

d

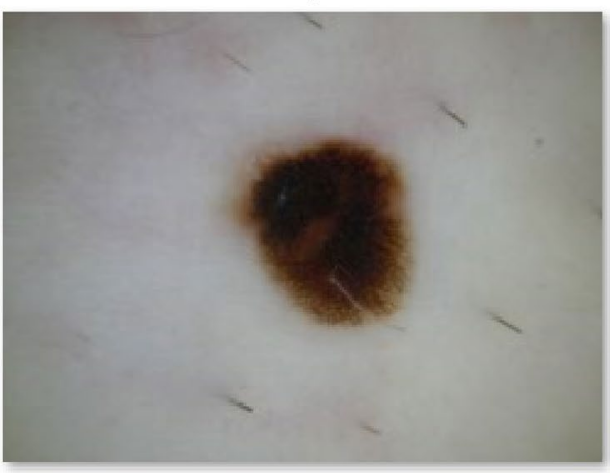

f

\section{Body distribution analyses}

The anatomical location was indicated for each case according to 16 anatomical sites (Table 2), including: scalp, ear, neck, shoulder, back, chest, abdomen, side, bottom, arm, forearm, back of the hand, tight, leg, ankle, back of the foot; six sites were grouped due to low size (i.e., ankle + back of the feet, scalp + ear and tight + leg). All 16 sites were then grouped into 4 anatomical areas: "upper extremities", "lower extremities", "posterior trunk", "anterior trunk".

\section{Statistical analysis}

Power analysis was performed with $\mathrm{G}^{*}$ power. In particular, a minimum sample size of 646 was estimated, based on $5 \%$ first type error, $80 \%$ power, three degrees of freedom and a very small effect size of 0.13 : this allowed us to identify small differences between \% as significant. Descriptive statistics was carried out over the whole dataset. Chi-squared test was performed to evaluate the association between the features' presence and the anatomical distribution. When association between clinical variables and body location was significant, multiple Fisher exact tests were performed to evaluate which groups were different from the other and the false discovery rate correction was performed to control 


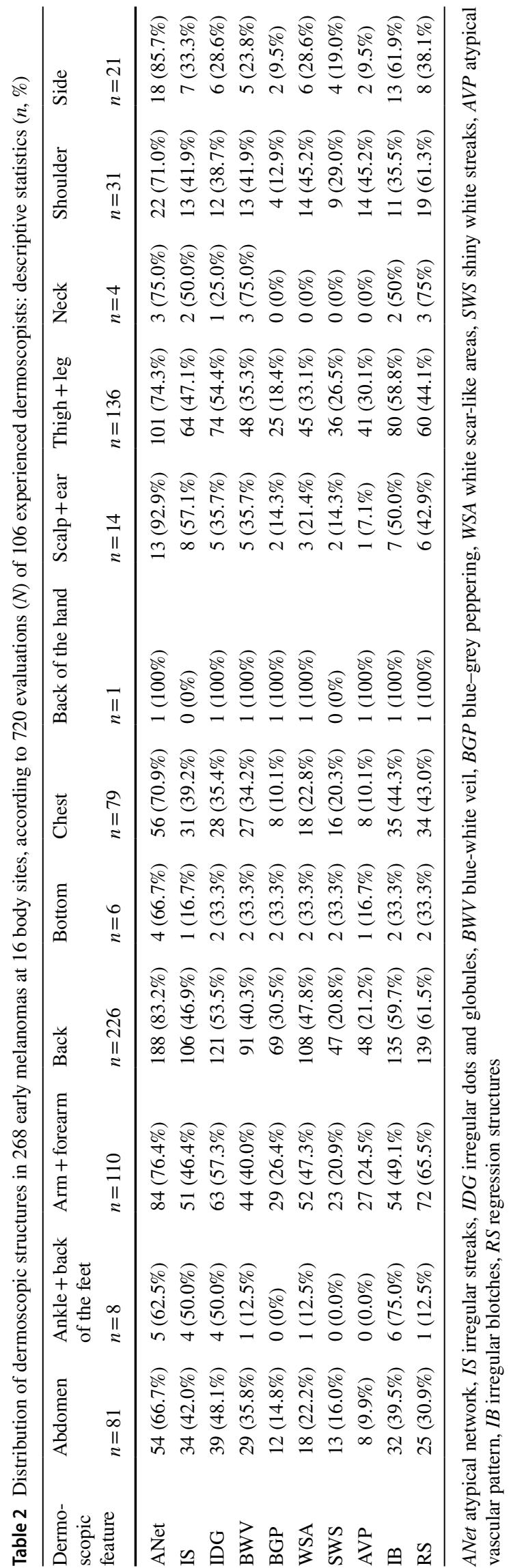

the type I error [4]. To further investigate, ANOVA and chisquared test were respectively carried out to assess the possible age and sex confounding in the evaluation of statistical differences between the four body area groups. If age and/or sex were confounding, post hoc multiple comparison with Tuckey's procedure and/or Fisher exact tests with false discovery rate correction were respectively performed. If age/ sex were confirmed as confounding factor a stratified analysis by sex/age was also carried out using the same tests of the overall analysis. Logistic regressions were performed to estimate the crude odds ratio (OR) and the adjusted odds ratio (aOR) with their $95 \%$ confidence interval $(\mathrm{CI})$. The OR described the association between dermoscopic features and body group (one vs the other); after that the OR was adjusted for age and sex. A $p$ value $<0.05$ was considered significant. The analyses were carried out by $\mathrm{R}$ version 3.3.3.

\section{Results}

The distribution of 10 dermoscopic structures in EMs located at 16 different body sites was reported in Table 2: the frequency of recognition is estimated according to 717 evaluations performed by 106 experienced dermoscopists. There was only one EM of the hand, showing all features except for IS and SWS. Excluding the head site (i.e., case number statistically not significant) the highest range of recognition was achieved by the AVP (9.9-45.2\%) followed by BWV and REG (same range of 12.5-75\%), and WSA (range $12-47.8 \%$ ).

In Table 3 were reported the rates of recognition of ten dermoscopic features of EMs grouped per anatomical area. In general, EMs of the anterior trunk exhibited ANet in $72.3 \%$ of cases, followed by IS (41\%) and IDG (40\%). EMs of the rear trunk exhibited ANet in $81.3 \%$ of cases, followed by IB (56\%) and IDG (50\%). Concerning EMs of the upper extremities, they showed ANet in $77 \%$ of cases, followed by RS (66\%) and IDG (58\%). As per lower extremities, the most common features were ANet (74\%), followed-by IB (60\%), IDG (54\%). The results of chi-square tests suggested that, when comparing anterior trunk vs rear trunk vs upper extremities vs lower extremities, six out of ten dermoscopic structures significantly differ in their distribution, i.e., IDG, BGP, WSA, RG, IB and VSA. According to the post hoc multiple comparisons, IDG, WSA and AVP showed three out of six significant paired comparisons. In particular, the distribution of AVP, IB and IDG was significantly higher on the rear trunk than on extremities and anterior trunk; RS was significantly higher on the rear trunk than on the anterior trunk/upper extremities; BGP was significantly higher on the rear trunk compared with the anterior trunk. No significant differences were found for ANet, IS and BWV according to 
Table 3 Distribution of dermoscopic structures in 268 early melanomas at 4 body areas, according to the dermoscopic evaluations $(N)$ of 106 experienced dermoscopists: descriptive statistics $(n, \%)$, Pearson X-square test $(p)$ and post hoc multiple comparison $(\mathrm{c}, \mathrm{e}, \mathrm{f})$

\begin{tabular}{llllll}
\hline $\begin{array}{l}\text { Body area } \\
\text { Body sites }\end{array}$ & $\begin{array}{l}\text { Upper extremities } \\
\text { Arm, forearm, } \\
\text { back of the hand }\end{array}$ & $\begin{array}{l}\text { Lower extremities } \\
\text { Thigh, leg, ankle, } \\
\text { back of the feet }\end{array}$ & $\begin{array}{l}\text { Rear trunk } \\
\text { Neck, ear, shoul- } \\
\text { der, back, bottom }\end{array}$ & $\begin{array}{l}\text { Anterior trunk } \\
\text { Chest, side, } \\
\text { abdomen, } \\
\text { scalp }\end{array}$ & \\
No. observation & $n=111$ & $n=144$ & $n=267$ & $n=195$ & \\
\hline 1. ANet & $85(76.6 \%)$ & $106(73.6 \%)$ & $217(81.3 \%)$ & $141(72.3 \%)$ & 0.113 \\
2. IS & $51(45.9 \%)$ & $68(47.2 \%)$ & $122(45.7 \%)$ & $80(41.0 \%)$ & 0.657 \\
3. IDG & $64(57.7 \%)$ & $78(54.2 \%)$ & $136(50.9 \%)$ & $78(40.0 \%)$ & $0.009^{\text {c,e,f }}$ \\
4. BWV & $45(40.5 \%)$ & $49(34.0 \%)$ & $109(40.8 \%)$ & $66(33.8 \%)$ & 0.315 \\
5. BGP & $30(27.0 \%)$ & $25(17.4 \%)$ & $75(28.1 \%)$ & $24(12.3 \%)$ & $0.000^{\mathrm{f}}$ \\
6. WSA & $53(47.7 \%)$ & $46(31.9 \%)$ & $124(46.4 \%)$ & $45(23.1 \%)$ & $0.000^{\text {ce, f }}$ \\
7. SWS & $23(20.7 \%)$ & $36(25.0 \%)$ & $58(21.7 \%)$ & $35(17.9 \%)$ & 0.469 \\
8. AVP & $28(25.2 \%)$ & $41(28.5 \%)$ & $63(23.6 \%)$ & $19(9.7 \%)$ & $0.000^{\text {c,e,f }}$ \\
9. IB & $55(49.5 \%)$ & $86(59.7 \%)$ & $150(56.2 \%)$ & $87(44.6 \%)$ & 0.021 \\
10. RS & $73(65.8 \%)$ & $61(42.4 \%)$ & $163(61.0 \%)$ & $73(37.4 \%)$ & $0.000^{\text {c,f }}$ \\
\hline
\end{tabular}

Multiple post hoc comparisons: upper extremities vs anterior trunk (c), lower extremities versus anterior trunk (e), rear vs anterior trunk (f)

ANet atypical network, $I S$ irregular streaks, $I D G$ irregular dots and globules, $B W V$ blue-white veil, BGP blue-grey peppering, $W S A$ white scar-like areas, $S W S$ shiny white streaks, $A V P$ atypical vascular pattern, $I B$ irregular blotches, $R S$ regression structures this classification. According to the ANOVA test, age did not prove to be a confounding factor: indeed, $p$ value was 0.06 and the mean age in each group was $\sim 55$ years. The association between sex and groups was instead significant (Chi-square test, $p=0.003$ ). In particular, the "Lower extremities" group was different from all the others and it was formed by $60 \%$ female and $40 \%$ male patients; instead, the other groups had $40 \%$ women and $60 \%$ men. The post hoc multiple comparison analysis showed that "Lower extremities" was statistically different from the "Upper trunk" $(p=0.015)$. However, the stratified results should be interpreted with caution due to the decreasing power into the groups (that is about $65 \%$ ).

The results of the association analysis between the ten dermoscopic features and the four anatomical distribution were reported in Table 4: crude odds ratios (OR) were calculated, along with adjusted odds ratio for sex and age (aOR). In the "upper extremities" area, the WSA feature was significantly prevalent compared with the other three body areas, according to OR and aOR; IS and IDG prevalence increased significantly with age (aOR). In the "lower extremities" area, the AVP feature was significantly prevalent, while the RS feature was significantly less represented than the other (OR $0.63 ; 95 \%$ CI 0.43-0.91) IS and IDG ORs were adjusted by age $(\mathrm{aOR})$ while IB by sex (women had a major prevalence of IB) and age. In the "posterior trunk", the features related to regression phenomenon such as RS, BGP and WSA were significantly prevalent according to both OR and aOR; moreover, IS and IDG ORs were adjusted by age (aOR) while IB by sex (women had a major prevalence of IB) and age. Finally, EMs in the "anterior trunk" area overall exhibited low rates of recognition of dermoscopic features: in particular, 6/10 features (IDG, BGP, WSA, AVP, IB, RS) were significantly less represented in the anterior trunk compared with other body areas.

\section{Discussion}

It is generally recognized that MM location depends on environmental, genetic, social and demographic factors. Among these, the sun-exposure factor is supposed to have a nonlinear relation with MM development, but rather a S-shaped curve: indeed, intermittent sun exposure seems to correlate with higher MM incidence before the age of 50, while in the elderly it is slightly prevalent on continuously exposed site, suggesting that an intermittently exposed body site can achieve the same pathogenetic doses as usually exposed skin $[2,8,10,30]$.

The analyses of distribution and association of ten dermoscopic features conventionally suggestive for malignancy, here carried out on a representative sample of de novo EMs, revealed several interesting findings.

First, the distribution analysis of dermoscopic features according to 16 body sites (Table 2) revealed that:

(a) EMs of the extremities exhibited the overall higher \% of dermoscopic features, compared with anterior trunk which appeared globally "featureless";

(b) Four out of ten dermoscopic features varied among body sites, specifically AVP, BWV, RS and WSA; AVP achieved the highest $\%$ on the shoulder and the lowest 
Table 4 Analysis of association between 717 observations of dermoscopic features and different body sites, grouped per anatomic body area: crude odds ratio (OR), adjusted odds ratio for sex and age
(aOR) and 95\% confidence interval (CI) are calculated for each body group versus all the other 3 groups

\begin{tabular}{|c|c|c|c|c|c|c|c|c|}
\hline \multirow{3}{*}{$\begin{array}{l}\text { Body area } \\
\text { Body sites }\end{array}$} & \multicolumn{2}{|c|}{ Upper extremities } & \multicolumn{2}{|c|}{ Lower extremities } & \multicolumn{2}{|l|}{ Posterior trunk } & \multicolumn{2}{|l|}{ Anterior trunk } \\
\hline & \multicolumn{2}{|c|}{ Arm, forearm, back of the hand } & \multicolumn{2}{|c|}{$\begin{array}{l}\text { Thigh, leg, ankle, back of the } \\
\text { feet }\end{array}$} & \multicolumn{2}{|c|}{$\begin{array}{l}\text { Neck, ear, shoulder, back, } \\
\text { bottom }\end{array}$} & \multicolumn{2}{|c|}{ Chest, side, abdomen, scalp } \\
\hline & OR (IC 95\%) & aOR (IC 95\%) & OR (IC 95\%) & aOR (IC 95\%) & OR (IC 95\%) & aOR (IC 95\%) & OR (IC 95\%) & $\mathrm{aOR}(\mathrm{IC} 95 \%)$ \\
\hline 1. ANet & $\begin{array}{l}1.00(0.62- \\
1.61)\end{array}$ & $\begin{array}{l}1.01(0.63- \\
1.64)\end{array}$ & $\begin{array}{l}0.82(0.54- \\
1.25)\end{array}$ & $\begin{array}{l}0.82(0.54- \\
1.24)\end{array}$ & $\begin{array}{l}1.54(1.06- \\
2.24)\end{array}$ & $\begin{array}{l}1.55(1.07- \\
2.26)\end{array}$ & $\begin{array}{l}0.73(0.50- \\
1.06)\end{array}$ & $\begin{array}{l}0.72(0.49- \\
1.05)\end{array}$ \\
\hline 2. IS & $\begin{array}{l}1.06(0.71- \\
1.59)\end{array}$ & $\begin{array}{l}1.05(0.70- \\
1.57)\end{array}$ & $\begin{array}{l}1.13(0.79- \\
1.63)\end{array}$ & $\begin{array}{l}1.12(0.78- \\
1.62)\end{array}$ & $\begin{array}{l}1.06(0.78- \\
1.44)\end{array}$ & $\begin{array}{l}1.07(0.78- \\
1.45)\end{array}$ & $\begin{array}{l}0.81(0.58- \\
1.13)\end{array}$ & $\begin{array}{l}0.82(0.59- \\
1.15)\end{array}$ \\
\hline 3. IDG & $\begin{array}{l}1.46(0.97- \\
2.20)\end{array}$ & $\begin{array}{l}1.47(0.98- \\
2.22)\end{array}$ & $\begin{array}{l}1.25(0.87- \\
1.81)\end{array}$ & $\begin{array}{l}1.24(0.86- \\
1.79)\end{array}$ & $\begin{array}{l}1.09(0.80- \\
1.47)\end{array}$ & $\begin{array}{l}1.10(0.81- \\
1.49)\end{array}$ & $\begin{array}{l}0.59(0.42- \\
0.82)\end{array}$ & $\begin{array}{l}0.58(0.42- \\
0.82)\end{array}$ \\
\hline 4. BWV & $\begin{array}{l}1.16(0.77- \\
1.76)\end{array}$ & $\begin{array}{l}1.18(0.78- \\
1.78)\end{array}$ & $\begin{array}{l}0.83(0.56- \\
1.22)\end{array}$ & $\begin{array}{l}0.83(0.57- \\
1.22)\end{array}$ & $\begin{array}{l}1.25(0.92- \\
1.71)\end{array}$ & $\begin{array}{l}1.25(0.92- \\
1.71)\end{array}$ & $\begin{array}{l}0.80(0.57- \\
1.14)\end{array}$ & $\begin{array}{l}0.79(0.56- \\
1.12)\end{array}$ \\
\hline 5. BGP & $\begin{array}{l}1.44(0.91- \\
2.29)\end{array}$ & $\begin{array}{l}1.46(0.92- \\
2.32)\end{array}$ & $\begin{array}{l}0.72(0.45- \\
1.16)\end{array}$ & $\begin{array}{l}0.72(0.45- \\
1.15)\end{array}$ & $\begin{array}{l}1.83(1.23- \\
2.63)\end{array}$ & $\begin{array}{l}1.85(1.29- \\
2.66)\end{array}$ & $\begin{array}{l}0.42(0.26- \\
0.68)\end{array}$ & $\begin{array}{l}0.42(0.26- \\
0.67)\end{array}$ \\
\hline 6. WSA & $\begin{array}{l}1.66(1.11- \\
2.50)\end{array}$ & $\begin{array}{l}1.66(1.11- \\
2.50)\end{array}$ & $\begin{array}{l}0.74(0.50- \\
1.10)\end{array}$ & $\begin{array}{l}0.74(0.50- \\
1.09)\end{array}$ & $\begin{array}{c}\mathbf{1 . 8 4}(1.35- \\
2.52)\end{array}$ & $\begin{array}{c}1.85(1.35- \\
2.52)\end{array}$ & $\begin{array}{c}0.40(0.28- \\
0.59)\end{array}$ & $\begin{array}{c}0.40(0.28- \\
0.59)\end{array}$ \\
\hline 7. SWS & $\begin{array}{c}0.97(0.59- \\
1.59)\end{array}$ & $\begin{array}{c}0.96(0.58- \\
1.58)\end{array}$ & $\begin{array}{l}1.31(0.86- \\
2.02)\end{array}$ & $\begin{array}{l}1.33(0.87- \\
2.05)\end{array}$ & $\begin{array}{c}1.05(0.73- \\
1.52)\end{array}$ & $\begin{array}{l}1.04(0.72- \\
1.51)\end{array}$ & $\begin{array}{c}0.76(0.50- \\
1.15)\end{array}$ & $\begin{array}{c}0.76(0.50- \\
1.16)\end{array}$ \\
\hline 8. AVP & $\begin{array}{l}1.33(0.83- \\
2.12)\end{array}$ & $\begin{array}{l}1.33(0.83- \\
2.13)\end{array}$ & $\begin{array}{c}1.68(1.10- \\
2.54)\end{array}$ & $\begin{array}{c}1.66(1.09- \\
2.52)\end{array}$ & $\begin{array}{c}1.27(0.88- \\
1.83)\end{array}$ & $\begin{array}{l}1.28(0.89- \\
1.85)\end{array}$ & $\begin{array}{l}0.32(0.19- \\
0.53)\end{array}$ & $\begin{array}{c}0.32(0.19- \\
0.53)\end{array}$ \\
\hline 9. IB & $\begin{array}{c}0.86(0.57- \\
1.29)\end{array}$ & $\begin{array}{c}0.86(0.57- \\
1.30)\end{array}$ & $\begin{array}{l}1.43(0.99- \\
2.07)\end{array}$ & $\begin{array}{c}1.40(0.97- \\
2.04)\end{array}$ & $\begin{array}{c}1.25(0.92- \\
1.69)\end{array}$ & $\begin{array}{l}1.27(0.93- \\
1.72)\end{array}$ & $\begin{array}{c}0.64(0.46- \\
0.89)\end{array}$ & $\begin{array}{c}0.64(0.46- \\
0.89)\end{array}$ \\
\hline 10. RS & $\begin{array}{c}2.0(1.31- \\
3.05)\end{array}$ & $\begin{array}{c}2.0(1.31- \\
3.05)\end{array}$ & $\begin{array}{c}0.63(0.43- \\
0.91)\end{array}$ & $\begin{array}{c}0.63(0.43- \\
0.91)\end{array}$ & $\begin{array}{c}1.84(1.35- \\
2.50)\end{array}$ & $\begin{array}{l}1.84(1.35- \\
2.50)\end{array}$ & $\begin{array}{l}0.45(0.32- \\
0.64)\end{array}$ & $\begin{array}{l}0.45(0.32- \\
0.64)\end{array}$ \\
\hline
\end{tabular}

ANet atypical network, $I S$ irregular streaks, $I D G$ irregular dots and globules, $B W V$ blue-white veil, $B G P$ blue-grey peppering, WSA white scarlike areas, $S W S$ shiny white streaks, $A V P$ atypical vascular pattern, $I B$ irregular blotches, $R S$ regression structures

$\%$ on the abdomen [15]; BWV and RS had the lowest $\%$ on the ankle/back of the feet and the highest $\%$ on the neck [1]; WSA presence was highest on the back and lowest on the ankle/back of the feet;

(c) ANet, IS and SWS features were homogeneously distributed within the EMs occurred at different sites (i.e., differential presence range $<30 \%$ ).

Second, the distribution analysis of dermoscopic features according to four anatomic body areas (Table 3), showed that:

(a) The posterior trunk had the highest frequencies of recognition of dermoscopic features related to regression and chronic traumatism (i.e., BGP, RS, WSA); [1, 15, 25, 29]

(b) The upper extremities showed a prevalence of early atypical lentiginous features (i.e., ANet, IS, IDG and IB); the AVP feature is significantly more prevalent in the extremities compared with the trunk; (c) All dermoscopic structures were overall poorly displayed by EMs of the anterior trunk.

Third, the association analysis of dermoscopic features according to four anatomical body areas adjusted per age and sex (Table 4) confirmed that:

(a) The IDG feature increased with age in all body areas;

(b) The IB feature was prevalent on the lower legs of females and increased with age;

(c) The regression features (i.e., BGP, RS, WSA) were significantly prevalent in the posterior trunk than in the three other groups, independently from age and sex;

(d) The anterior trunk was "featureless" for six out of ten dermoscopic features.

Taken together, the present findings could be, at least partially, interpreted according to the hypothesis of a nonlinear but S-shaped correlation between MM body distribution and UV-cumulative rates $[3,7,8]$, that could explain: 
the higher rates of lentiginous-related features-ANet and IS on the chronically exposed upper extremities, and the predominance of IDG and IB at lower extremities and posterior trunk, intermittently exposed. In particular, the IB feature can be regarded as indicative of EM when detected in the lower female leg with advanced age, while the IDG feature increased with age independently from the body location, as a superficial-growing-related feature. In addition, MM of the anterior trunk seem to be featureless at early stages according to the dermoscopic features conventionally assumed as suggestive of malignancy. Thus, it could be questioned if the current pattern analysis could not sufficiently and accurately detect EMs arising on the anterior trunk, especially photoprotected areas such as the abdomen and the side.

This study had several limitations. First, although the number of EMs lesions selected was enough to obtain a power of $80 \%$, the power decreased to $65 \%$. Stratifying into male and female subgroups. Some body sites (head, neck, ankle/back of the feet) had a lower number of cases compared with the other more represent sites (i.e., back, legs): however, we preferred not to normalize all 16 body sites groups with the same number of lesions, but to maintain the collection rate to respect the distribution of EMs encountered in clinical practice. It should be also underlined that dermoscopists were blinded for the histological diagnosis but were aware of the exact body site, also having the clinical picture of the body area available in the tele-dermoscopic test: it may be questioned if this fact could somehow affect the dermoscopic assessment but was specifically designed to reproduce the daily activity of dermatologists in clinical practice.

\section{Conclusions}

The body location has an impact on the dermoscopic appearance of EM. Globally, EMs on the extremities show a variable prevalence of the dermoscopic features that are conventionally referred to as indicative of malignancy. These are which are difficult to observe in EMs arising on the abdomen, chest and side in the early stages. The EMs on the lower leg of women showed an age-related increase of the irregular blotches feature. Further studies focused on a broader data set of trunk EMs may be needed to provide new dermoscopic features that can detect malignant changes in the early stages.

Author contributions LT: conception/design; data acquisition and interpretation; literature review; manuscript draft and review; approval of final manuscript. AC: data analysis and interpretation; manuscript draft and review; approval of final manuscript. EM, EC: literature review; manuscript review; approval of final manuscript. FF, CC, AL,
DT, CL, SP, JLP, GA, GP: manuscript draft and review; approval of final manuscript. GC, AB, BC, PR: conception/design; data acquisition and interpretation; manuscript draft and review; approval of final manuscript. All authors agree to be accountable for all aspects of the work in ensuring that questions related to the accuracy or integrity of any part of the work are appropriately investigated and resolved.

Funding Open access funding provided by Università degli Studi di Siena within the CRUI-CARE Agreement.

\section{Declarations}

Conflict of interest The authors have no conflict of interest to declare.

Research involving human and animal participants All procedures performed in this study involving human participants were in accordance with the local ethical committee and with the 1964 Helsinki Declaration and its later amendments or comparable ethical standards.

Open Access This article is licensed under a Creative Commons Attribution 4.0 International License, which permits use, sharing, adaptation, distribution and reproduction in any medium or format, as long as you give appropriate credit to the original author(s) and the source, provide a link to the Creative Commons licence, and indicate if changes were made. The images or other third party material in this article are included in the article's Creative Commons licence, unless indicated otherwise in a credit line to the material. If material is not included in the article's Creative Commons licence and your intended use is not permitted by statutory regulation or exceeds the permitted use, you will need to obtain permission directly from the copyright holder. To view a copy of this licence, visit http://creativecommons.org/licenses/by/4.0/.

\section{References}

1. Borsari S, Pampena R, Raucci M et al (2019) Neck melanoma: clinical, dermoscopic and confocal features. Dermatology 8:1-7. https://doi.org/10.1159/000503284

2. Cho E, Rosner BA, Colditz GA (2005) Risk factors for melanoma by body site. Cancer Epidemiol Biomark Prev 14(5):1241-1244. https://doi.org/10.1158/1055-9965.EPI-04-0632

3. Clark LN, Shin DB, Troxel AB, Khan S, Sober AJ, Ming ME (2007) Association between the anatomic distribution of melanoma and sex. J Am Acad Dermatol 56(5):768-773. https://doi. org/10.1016/j.jaad.2006.12.028

4. Cox KM, Coretta HK (1993) Post hoc pairwise comparisons for the chi-square test of homogeneity of proportions. Educ Psychol Measur 53(4):951-962. https://doi.org/10.1177/0013164493 053004008

5. Crombie IK (1983) Distribution of malignant melanoma on the body surface. Br J Cancer 43:842-849. https://doi.org/10.1038/ bjc. 1981.123

6. Darmawan CC, Jo G, Montenegro SE et al (2019) Early detection of acral melanoma: a review of clinical, dermoscopic, histopathologic, and molecular characteristics. J Am Acad Dermatol 81(3):805-812. https://doi.org/10.1016/j.jaad.2019.01.081

7. Elwood JM, Gallagher RP (1998) Body site distribution of cutaneous malignant melanoma in relationship to patterns of sun exposure. Int J Cancer 78(3):276-280. https://doi.org/10.1002/(SICI) 1097-0215(19981029)78:3\%3c276::AID-IJC2\%3e3.0.CO;2-S

8. Elwood JM, Gallagher RP (1983) Site distribution of malignant melanoma. Can Med Assoc J 128(12):1400-1404 
9. Gershenwald JE (2017) Melanoma staging: Evidence-based changes in the American Joint Committee on Cancer eighth edition cancer staging manual. CA Cancer J Clin 67(6):472. https:// doi.org/10.3322/caac.21409

10. Ghiasvand R, Robsahm TE, Green AC et al (2019) Association of phenotypic characteristics and UV radiation exposure with risk of melanoma on different body sites. JAMA Dermatol 155(1):39-49. https://doi.org/10.1001/jamadermatol.2018.3964

11. Holman CDJ, Mulroney CD, Armstrong BK (1980) Epidemiology of pre-invasive and invasive malignant melanoma in Western Australia. Int J Cancer 25:317-323. https://doi.org/10.1002/ijc. 2910250303

12. Klepp O, Magnus K (1979) Some environmental and bodily characteristics of melanoma patients. A case-control study. Int $\mathbf{J}$ Cancer 23:482-486. https://doi.org/10.1002/ijc.2910230407

13. Kittler H, Pehamberger H, Wolff K, Binder M (2002) Diagnostic accuracy of dermoscopy. Lancet Oncol 3:159-165. https://doi.org/ 10.1016/S1470-2045(02)00679-4

14. Kittler H (2008) Early recognition at last. Arch Dermatol 144:533-534. https://doi.org/10.1001/archderm.144.4.533

15. Lallas A, Longo C, Manfredini M et al (2018) Accuracy of dermoscopic criteria for the diagnosis of melanoma in situ. JAMA Dermatol 154(4):414-419. https://doi.org/10.1001/jamadermatol. 2017.6447

16. Lallas A, Sgouros D, Zalaudek I et al (2014) Palmar and plantar melanomas differ for sex prevalence and tumor thickness but not for dermoscopic patterns. Melanoma Res 24(1):83-87. https://doi. org/10.1097/CMR.0000000000000037

17. Larsen TE, Grude TH (1979) A retrospective histological study of 669 cases of primary cutaneous malignant melanoma in clinical stage I. 7. The relative prognostic value of various clinical and histological features. The result of a stepwise multiple regression analysis of 553 of these cases. Acta Pathol Microbiol Scand 87:469-477

18. Lee JAH, Yongchaiyudha S (1971) Incidence of and mortality from malignant melanoma by anatomical site. J Natl Cancer Inst 47:253-263. https://doi.org/10.1093/jnci/47.1.253

19. McLeod GR (1975) Factors influencing prognosis in malignant melanoma. Prog Clin Cancer 6:177-182

20. National Comprehensive Cancer Network (2019) Melanoma. In: NCCN Clinical Practice Guidelines in Oncology Version 1.2020 9. Available via DIALOG. http://www.nccn.org/professionals/ physician_gls/pdf/melanoma.pdf. Accessed 23 Mar 2020

21. Pralong P, Bathelier E, Dalle S et al (2012) Dermoscopy of lentigo maligna melanoma: report of 125 cases. Br J Dermatol 167:280 287. https://doi.org/10.1111/j.1365-2133.2012.10932.x

22. Rubegni P, Tognetti L, Argenziano G et al (2016) A risk scoring system for the differentiation between melanoma with regression and regressing nevi. J Dermatol Sci 83(2):138-144. https://doi. org/10.1016/j.jdermsci.2016.04.012

23. Schiffner R, Schiffner-Rohe J, Vogt T et al (2000) Improvement of early recognition of lentigo maligna using dermatoscopy. J Am Acad Dermatol 42:25-32. https://doi.org/10.1016/s0190-9622(00) 90005-7

24. Thune I, Olsen A, Albrektsen G et al (1998) Cutaneous malignant melanoma: association with height, weight and body-surface area: a prospective study in Norway. Int J Cancer 55(4):555-561. https://doi.org/10.1002/ijc.2910550406

25. Tognetti L, Cevenini G, Moscarella E et al (2018) An integrated clinical-dermoscopic risk scoring system for the differentiation between early melanoma and atypical nevi: the iDScore. J Eur Acad Dermatol Venereol 32(12):2162-2170. https://doi.org/10. $1111 /$ jdv. 15106

26. Tognetti L, Cinotti E, Perrot JL, Campoli M, Fimiani M, Rubegni P (2018) Benign and malignant collision tumors of melanocytic skin lesions with hemangioma: Dermoscopic and reflectance confocal microscopy features. Skin Research and Technology 24(2):313-317. https://doi.org/10.1111/srt.12432

27. Tognetti L, Fiorani D, Tonini G et al (2020) Dermoscopy: fundamentals and technology advances. In: Fimiani M, Rubegni P, Cinotti E (eds) Technology in practical dermatology, photorejuvenation: concepts, practice, perspectives, 1 st edn. Springer Nature, Germany, pp 3-24

28. Tognetti L, Cartocci A, Cinotti E et al (2020) The impact of anatomical location and sun exposure on the dermoscopic recognition of atypical nevi and early melanomas: usefulness of an integrated clinical-dermoscopic method (iDScore). J Eur Acad Dermatol Venereol. https://doi.org/10.1111/jdv.16847

29. Tognetti L, Cevenini G, Moscarella, et al (2020) Validation of an integrated dermoscopic scoring method in an European teledermoscopy web platform: the iDScore project for early detection of melanoma. J Eur Acad Dermatol Venereol 34:640-647. https:// doi.org/10.1111/jdv.15923

30. Wee E, Wolfe R, Mclean C, Kelly JW, Pan Y (2019) The anatomic distribution of cutaneous melanoma: A detailed study of 5141 lesions. Australas J Dermatol 61(2):125-133. https://doi.org/10. 1111/ajd.13223

Publisher's Note Springer Nature remains neutral with regard to jurisdictional claims in published maps and institutional affiliations. 